\title{
DE ZIN VAN HET ECONOMISCHE OPNIEUW BESCHOUWD
}

In 1950 heb ik het hoogleraarschap in de economie aan de juridische faculteit der Vrije Universiteit te Amsterdam aanvaard met een rede over de zin van het economische. Sindsdien heeft dit centraal methodologisch vraagstuk van de wetenschap der economie mij ook verder bezig gehouden. Het is voor een economist een moeilijk vraagstuk, omdat het tevens een wijsgerig vraagstuk is. Over het algemeen vindt de cconomist daarover veinig in de filosofische literatuur. Dit is zeer begrijpelijk, want wijsgeren kumien op zijn best maar heel summier kennis nemen van wat er in de vakwetenschappen omgaat, terwijl zij, voor zover mij bekend, in den regel slechts weinig belangstelling voor de economic aan den dag leggen. Omgekeerd zijn economisten meestal niet bijzonder filosufisch aangelegd, en hebben zij de handen vol om de stormachtige ontwikkeling van hum eigen literatuur enigzins bij te houden afgezien nog van het feit dat zij in den regel vele praktisch beslommeringen hebben, ten gevolge waarvan zij zich niet ongestoord aan de studic kunnen wijden. Van een behoorlijk samenspel tussen filosofen en economisten komt over het geheel ook niet veel terecht. Wat de wijsgerige kant van mijn overpeizingen betreft, ben ik dus door de nood gedwongen slechts amateur. Ik kom daar gaarne voor uit, en ik ben steeds bereid te zwichten voor het beter oordeel der wijsgeren, mits ik dat kan vatten, en in mijn eigen werk daar iets mee uit kan richten. Men behoeft nog geen door de wol geverfd prag. matist of operationalist te zijn om te weten dat ieder werk zijn eigen eisen stelt.

Het zeldzame geval van een interdisciplinaire discussie over de eigen aard van het economische heeft van juli 1958 tot september 1959 in dit tijdschrift plaats gehad. Dr. F. J. du Plessis heeft daarbij op voortreffelijke wijze de rol van de economist vervuld, prof. L. J. du Plessis schreef als socioloog en jurist, terwijl prof. dr. H. G. Stoker als wijsgeer de discussie opende en sloot. Collega Stoker was zo vriendelijk mij verleden jaar de desbetreffende nummers te doen toekomen, en collega Coetzee bracht mij het verzock van de Redactie over, naar aanleiding daarvan mijn bevindingen neer te schrijven. Ik heb dit gaarne op mij genomen, en nu ik einde- 
lijk gelegenheid heb gevonden mijn belofte in te lossen, lijkt het mij het beste een beknopte thetische uiteenzetting van mijn denkbeelden te geven. Ik teken daarbij aan, dat ik het niemand kwalijk zal nemen wanneer hij deze denkbeelden onjuist of van weinig betekenis acht. Ik denk dat wij op dit grensgebied van wijsbegeerte en economie wel altijd uiteenlopende visies zullen aantreffen, en ik meen dat wij dit moeten aanvaarden. Misschien zijn er die dit defaitistisch van mij vinden, of die mij van subjectivisme of relativisme zullen verdenken, maar ik meen dat wij niet om de lieve vrede elkanders denkbeelden moeten aanvaarden, ook al spreken zij ons niet zo bijzonder toe.

Om dan maar van wal te steken, wil ik er allereerst op wijzen dat het economische, waarvan wij de zin zoeken te benaderen, een aspect is van al het menselijk handelen en van alle menselijke instellingen. Voorts zijn er bepaalde soorten van handelingen en instellingen, waarvoor het economisch aspect kwalificerend, d.w.z. van centrale betekenis is. Men zegt dat de wetenschap der economie een aspectswetenschap is in die zin dat zij zich bezig houdt met de analyse van het economisch aspect als zodanig. Ik geloof echter dat zij daar niet lang mee kan volstaan, want het economisch aspect komt in de werkelijkheid altijd tezamen met andere aspecten voor, en wetenschap houdt zich met werkelijkheid bezig. Ik zou liever zeggen, dat de wetenschap der economie zich in hoofdzaak toelegt op bestudering van de economisch gekwalificeerde handelingen en instellingen, en de daarmee rechtstreeks verband houdende verschijnselen, waarbij dus van belang is er rekening mee te houden dat ook niet-economische aspecten in die handelingen, instellingen en andere verschijnselen aanwezig zijn.

Het geheel van economisch gekwalificeerde handelingen, instellingen en daarmee rechtstreeks verband houdende verschijnselen kunnen wij de economische levenskring noemen. Deze term duidt op een statische beschouwing. Willen wij rekening houden met het tijdsverloop, dan kunnen wij beter spreken van een economische levensstroom. Buiten de economische kring en buiten de economische stroom bevinden zich op andere wijze, d.w.z. door andere aspecten gekwalificeerde, kringen en stromen. In het naast elkaar bestaan van deze kringen en stromen komt de maatschappelijke arbeidsverdeling tot uitdrukking. De kringen zweven echter niet los van 
elkaar in de ruimte, en de stromen zijn niet van clkaar gescheiden. Integendeel, zij zijn slechts globaal van elkaar te onderscheiden, want de kringen overvleugelen elkaar en de stromen vloeien in één bedding. Men zou kunnen denken aan een brede rivier waarin water van verschillende tint uit verschillende beken samenvloeit en de eigen kleur nog een tijdlang behoudt. Geen enkele kring of stroom is autonoom in die zin dat zij de andere niet nodig zou hebben: zij voorzien elkaar wederkerig van elkanders diensten. Wat de verhouding tussen kring en stroom betreft, kunnen wij het ons misschien het beste zó voorstellen, dat de kring de doorsnede van de stroom is.

Aan de wortel van deze beschouwing van de maatschappi $j$ ligt het aspectsbegrip. Met aspect bedoel ik hier niet een willekeurig gezichtspunt, waaronder men iets kan bezien. Het gaat hier om fundamentele aspecten, die onmisbaar zijn voor het bij benadering vatten van het menselijk leven. Aan de onderscheiding van deze fundamentele aspecten ligt ten grondslag de gedachte, dat voor het menselijk leven essentieel is dat de mens van Godswege geroepen is: hierin ligt de grond en de oorsprong van de zin van het leven. Voorts is van grote betekenis dat de mens een bepaalde substantic, structuur en functie heeft. Ik bedoel hiermee dat het menselijk ik in relatie staat tot God, de medemens, het zelf en de dingen, en dat het in elk dezer relaties op drieërlei wijze functioneert, namelijk kennend, liefhebbend en dienend. Men kan hier denken aan het drievoudig ambt van profeet, priester en koning, waarmee de mens is bekleed, waartoe hij ook met verstand, gevoel en wil is toegerust.

Tot het kennen, liefhebben en dienen van God behoort het luisteren naar $\mathrm{Zijn}$ roepstem, het verwachten van $\mathrm{Zijn}$ $\mathrm{Rijk}$, en het ontwikkelen van de gaven en krachten die $\mathrm{Hij}$ in Zijn schepping heeft neergelegd. Tot het kennen, liefhebben en dienen van de medemens behoort het in gemeenschap openstaan voor hem, en het van harte gaarne bijstand verlenen aan hem om hem in zijn menselijke waardigheid tot zijn recht te doen komen. Tot het kennen, liefhebben en dienen van zichzelf behoort het critisch openstaan voor de eigen mogelijkheden, en het met toewijding ontwikkelen van de door God geschonken talenten. Tot het kennen, liefhebben en dienen van de dingen behoort het onderscheiden van het menselijk levensmilieu naar zijn verscheiden aard, en het met zorg 
en overleg aanwenden daarvan tot verheffing van het menselijk leven en samenleven.

Het is dus een veelzijdige opdracht, waartoe de mens in het hier en nu van zijn situatie geroepen is. De fundamentele normatieve aspecten van zijn roeping komen gelijktijdig tot hem. In zijn handelen is hij geroepen tot een simultane verwerkelijking van deze complexe normativiteit. Faalt hij hierin, d.w.z. absoluteert hij een bepaalde norm of een bepaalde relatie, met gelijktijdige relativering van de overige, dan draagt het werk dat uit zijn handen komt, namelijk instellingen, goederen, diensten, wetten, begrippen, theorieën en dergelijke, daarvan het stempel. Het milieu, de situatie, trekt in een bepaalde richting scheef. Het water van de levensstroom krijgt een bepaalde overheersende kleur, in plaats van het gamma van alle tinten te vertonen. Niettemin blijft steeds Gods roepstem tot de mens uitgaan, om de situatie te redden en in de goede richting te ontwikkelen.

Men kan de economische levensstroom dus naar zijn wezen verstaan als het resultaat van een economisch gekwalificeerd streven van de mensen tot realisatie van een veelzijdige normativiteit, waarbij men zich die stroom dan moet voorstellen als met op andere wijze gekwalificeerde levensstromen in één bedding voortvloeiend. Men kan het economisch aspect verstaan als een onmisbare schakel in een fundamentele veelzijdige normativiteit, die simultane realisatie in iedere concrete situatie vraagt. De actuele situatie der samenleving, en de voortdurende verandering daarvan door menselijke inspanning, kan men verstaan als een strijd tussen waarheid en leugen, liefde en haat, dienst en heerschappij, welke beginselen in alle relaties op leven en dood om de overhand worstelen: het is de strijd tussen de Geest van Christus en de geest uit de afgrond, met als inzet de harten der mensen. Het schijnt alsof de vervreemding van God, van de naaste, van zichzelf en van de dingen door ons menselijk toedoen somtijds de overhand verkrijgt, maar ondanks het bederf der situatie weten wij dat Christus overwinnaar is. De troost van het Evangelie is, dat er vergeving is en dat wij telkens een nieuw begin mogen maken.

De goddelijke roeping heeft een veelkleurige inhoud. $\mathrm{Zij}$ vraagt om een simultaan streven naar verbetering van het levensmilieu, naar ontplooiing der eigen persoonlijkheid, naar 
gemeenschap, gerechligheid en naastenliefde in de verhouding tot de medemens, terwijl dit alles dient te geschieden met een goed inzicht in de aard der dingen en door daadwerkelijke beschikking over de dingen. Onder de dingen moeten worden verstaan de gaven en krachten der natuur, alsmede de daaruit door menselijke arbeid gevormde stoffelijke en onstoffelijke cultuurgoederen. De daadwerkelijke beschikking over de dingen is er op gericht, door voortgaande vormingsarbeid daaruit verdere cultuurgoederen te winnen. $\mathrm{Nu}$ komt de roeping tot economisch verantwoord leven in het bijzonder dáárin tot uitdrukking, dat deze beschikking over de dingen niet slechts op een goed inzicht in de aard der dingen berust, maar daarenboven met zorg en overleg, met liefde voor de dingen, geschiedt. Hier naderen wij het belangrijke onderscheid tussen de aard van het economische en de aard van de techniek en de organisatie.

Techniek is het rangschikken van dingen naar hun aard, ten behoeve van hun gebruik of aanwending als middelen ter bereiking van een bepaald doel, waarbij onder doel moet worden verstaan de voorstelling van een bepaalde gewenste verandering in de situatie. Organisatie verschilt van techniek dáárin dat bij organisatie niet alleen dingen maar ook mensen worden gerangschikt, teneinde als middelen ter bereiking van een gegeven doel te worden aangewend. Verstandelijk inzicht in de aard der middelen en beschikkingsmacht over de middelen zijn in techniek en organisatie voorondersteld. Maar het daadwerkelijk beschikken over en het aanwenden van middelen is eerst economisch verantwoord, wanneer het in overeenstemming met de economische norm geschiedt. Er is een bepaald sóórt zorg en overleg nodig, die van bloot rationeel inzicht is te onderscheiden. Bij dit overleg speelt de waardering der middelen en doeleinden een belangrijke rol. Het handelen, met behulp van techniek en organisatie, gebaseerd op kennis van zaken, en steunend op bereidheid tot beschikking en aanwending, dient immers zodanig te zijn dat de gewenste situatie inderdaad een verbetering is in vergelijking met de bestaande.

Want aan het handelen is inherent, dat wanneer het doel is bereikt, de middelen niet meer beschikbaar zijn. Men kan het ook zó zeggen, dat de bereiking van het doel betekent dat het doel is opgeheven, en dat er een verandering in de samenstelling van de middelenvoorraad is opgetreden. Met het oog 
op verder handelen, ter bereiking van nieuwe doeleinden, ter verdere verbetering van de situatie, is het gewenst dat iedere verandering in de samenstelling van de middelenvoorraad een stap vooruit betekent. Dc mens die handelt moet dus de waarden die hij aanwendt, afwegen tegen de waarden die hij door zijn handelen verwacht te verkrijgen. Hij moet offer en nut, kosten en resultaat, met elkaar vergelijken om te zien of er een toeneming van waarde zal zijn. Het gaat er dus niet om, de middelen zuinig te beheren en daardoor op de kosten te sparen, want bij een zeer groot en waardevol resultaat kan het beter zijn geen kosten te ontzien. Het gaat ook niet om een vereffening van waarden, integendeel, wanneer er geen waardenaccres is te verwachten bij een bepaalde handeling, zal het beter zijn de middelen in een andere, meerbelovende richting aan te wenden. Hoe groter de toeneming van waarde, des te beter komt de menselijke waardigheid tot haar recht, d.w.z. op des te betere wijze word de roeping beantwoord.

Het economische, dat naar zijn diepste zin kan worden beschouwd als gekenmerkt door liefde tot de dingen, dringt tot waardering en afweging van waarden, teneinde tot een verantwoorde aanwending van middelen te komen. Wij stuiten hier op het verschijnsel van de schaarste der middelen. Dit wil niet zeggen dat er in absolute zin weinig middelen zijn, want de situatie is één en al middel. Het verschijnsel van de schaarste hangt dáármee samen, dat de verandering in de samenstelling van de middelenvoorraad die het handelen teweegbrengt, niet slechts technisch of organisatorisch mogelijk, maar ook uit een oogpunt van levensontplooiing wenselijk moet zijn. Men drukt dit vaak zó uit, dat er een zo groot mogelijke bevrediging van behoeften moet zijn. Dan verstaat men onder behoeften de eerste keuze van mogelijke doelstellingen, waarvan bij nadere keuze moet worden uitgemaakt, welke het méést urgent zijn. Het economisch handelen wordt dan ook wel keuzehandelen genoemd. Naar mijn mening moet men hiermee voorzichtig zijn, omdat kiezen of beslissen een menselijk gebeuren is dat ook op andere dan economische wijze, namelijk sociaal, ethisch, juridisch of anderszins gekwalificeerd kan zijn.

Om ons tot het economisch handelen te bepalen, nemen wij een ogenblik aan: een bepaalde eerste keuze van denkbare doeleinden. Het is zeer wel mogelijk, dat de in gerede vorm aan- 
wezige voorraad middelen voor de onmiddellijke en volledige bevrediging van die behoeften niet toereikend is. Dit is dan de schaarste die tot een keuze, en tot uitstel van bevrediging van minder dringende behoeften noopt. Het gebruik van de term zuinigheid of spaarzaamheid, als kernbegrip van het economische, is daaruit voortgekomen. Daar staat echter tegenover dat wanneer wij ons uitgangspunt kiezen in gegeven behoeften en gegeven middelen, ons begrip van het economische een statisch karakter heeft gekregen. Dit begrip geeft wel verheldering, maar het bevat een aanzienlijke vereenvoudiging. Daarom wil ik óók denken aan een meer fundamenteel begrip van schaarste, d.w.z. een schaarste die inherent is aan het menselijk leven, en die verband houdt met het feit dat de mens naar zijn aard gebonden is aan plaats en tijd.

Aangezien verplaatsing onder aanwending van energie in de tijd kan geschieden, is het allereerst de tijdgebondenheid van de mens die in het begrip schaarste ligt besloten. De menselijke tijd is schaars, omdat de mens een opdracht heeft, die van boventijdelijke oorsprong is. Voorts is de voor de menselijke activiteit beschikbare hoeveelheid energie in beginsel beperkt: er zijn grenzen aan het menselijk vermogen gesteld. Het economische is er op gericht, dat de mens zijn tijd en kracht op zodanige wijze zal aanwenden, dat hij aan zijn roeping zoveel mogelijk beantwoordt. De op een bepaald moment in een historische situatie als meest urgent gepresenteerde doeleinden behoeven niet zonder meer als de gegeven behoeften te worden beschouwd. Het economische wekt op tot geregelde herziening van de waardering, in confrontatie met de meta-economische normativiteit, teneinde tot een verantwoorde simultane reactie op de situatie te komen. En het stimuleert ook tot een geregelde besinning over de samenstelling en het tempo van beskikbaarstelling van de gerede middelenvoorraad.

Ik zou nog enige tijd kunnen voortgaan met amateuristisch filosoferen over de aard en de eigenschappen van het economische. Voor het ogenblik acht ik het echter nodiger, te komen tot een handzaam symbool, tot een kort samenvattende term, om de zin van het economische mee aan te duiden. Daarvoor heb $\mathrm{ik}$ het woord doelmatigheid gekozen, en ik maak daarmee allerlei kritiek los. Zo wordt opgemerkt dat doelmatigheid een veel te algemeen begrip is, dat ook 
in andere levenskringen dan de economische een rol speelt, en zelfs buiten het bereik van de normatieve roeping vóorkomt, in het rijk der natuur, waar men de teologie als reciproke van de natuurwettelijke causaliteit aantreft. Ik merk ten eerste op, dat ook de zinkernen der overige normatieve aspecten zeer algemene begrippen zijn. Men hoort soms over vaagheid van de algemene beginselen van het menselijk leven klagen. Naar mijn mening berust dit op een misverstand. De algemeenheid of vaagheid wil juist het typische karakter van de norm tot uitdrukking brengen, namelijk het zijn van een oproep aan de mens om in vrijheid tot positivering te komen.

Het vóórkomen van het begrip doelmatigheid in de nieteconomisch gekwalificeerde levenskringen behoeft geen verwondering te wekken. De economische norm stelt in alle menselijke levenskringen en levensstromen haar eis. Zoals ook omgekeerd de kwalificerende normen van de respectieve nieteconomische kringen en stromen in de economische kring en stroom haar eis doen horen. In het rechtsleven bijvoorbeeld is doelmatigheid nodig, evenals in het economisch leven gerechtigheid. De onderneming is een economisch gekwalificeerde instelling, die economisch gekwalificeerde handelingen verricht. Hoewel deze handelingen door de cconomische norm der doelmatigheid zijn getypeerd, moeten zij toch óók voldoen aan de geschreven en ongeschreven regels die binnen de onderneming en tussen de ondernemingen bestaan, teneinde de rechtvaardigheid in het verkeer tussen de handelende personen te bevorderen.

Het spreken van doelmatigheid in het rijk der natuur doet mij allereerst denken aan de constantheid van de natuurwetten, tengevolge waarvan de mens in zijn techniek en organisatie gebruik kan maken van de gaven en krachten die in de schepping zijn neergelegd. Hij kan deze gaven en krachten in de staat waarin hij ze aantreft, of na een min of meer diepgaande bewerking, als middelen aanwenden. Hebben zij geen of weinig bewerking nodig, dan kan hij ze gemakkelijk gebruiken. Nocmt hij ze daarom doelmatig, dan is dit eigenlijk cen onjuist spraakgebruik, want in de natuur is geen doelmatigheid, de natuur handelt niet en heeft geen doel. Het is beter van bruikbaarheid, namelijk met het oog op menselijke cultuurdoeleinden, te spreken.

Een ander bezwaar tegen het begrip doelmatigheid als 
economische norm is, dat de techniek en de organisatie de specifieke terreinen der doelmatigheid zouden zijn. Nou zou ik voor de techniek liever van doeltreffendheid, voor de organisatie liever van doelgerichtheid willen spreken, al geef ik toe dat doeltreffendheid en doelgerichtheid beide tot doelmatigheid in ruime zin behoren. $\mathrm{Zij}$ hebben echter betrekking op een bijzonder geval, namelijk dat van de verhouding tussen middelen en één concreet doel. Ik zou dus wel binnen de techniek en de organisatie de economische norm der doelmatigheid willen herkennen, maar dan bij wijze van spreken in een embryonale toestand, als een soort van antecipatie, hoewel dit woord in mijn conceptie van simultaniteit minder goed past. Ik denk namelijk bij doelmatigheid in haar volle zin niet alleen aan de aanwending van middelen bij één gegeven doel, maar ook aan verantwoorde keuze van doeleinden. Er is ook economische doelmatigheid in het doelstellen nodig, aangezien immers ieder doel na bereiking middel wordt voor verdergelegen doeleinden.

Er wordt ook op gewezen, dat er een onderscheid moet worden gemaakt tussen objectieve en subjectieve doelmatigheid. Er kan subjecticve doelmatigheid zijn met objectieve doelmatigheid of ondoelmatigheid, en objectieve doelmatigheid met subjectieve doelmatigheid of ondoelmatigheid. Het kan bijvoorbeeld zijn, dat het handelen ondanks onvoldoende kennis en inzicht, ten gevolge van een meevaller van buitenaf toch tot een gunstige toestand leidt. Of met handelen kan op correct inzicht en op een goede kennis van de wetten van oorzaak en gevolg berusten, en door onvoorziene omstandigheden tot een teleurstellend resultaat leiden. Het zou dan beter zijin, van doelmatigheid van het menselijk handelen alleen achteraf te spreken, namelijk als de bereikte toestand niet achterblijft bij de gewenste. Ik meen echter, dat dezc beschouwingswijze het economische verwart met het rationele. Inzicht en kennis duiden op overeenstemming met de rationele norm. Het menselijk verstand komt tot kennis en inzicht door logische redenering, theoretische analyse en intellectuele intuïtie, aan de hand van waargenomen verschijnselen. Dit inzicht en deze kennis zijn, liefst zo correct mogelijk, bij het menselijk en dus ook bij het economisch handelen van grote betekenis. Maar het economisch aspect, met zijn doelmatige afweging van waarden in verband met de schaarste, is een zelfstandig aspect, náást het rationele. Slechts wanneer alle waarden ééns voor 
goed tol éénzelfde noemer konden worden herleid en met éénzelfde maatstal gemeten, zou het economisch aspect met het rationele samenvallen, maar aan deze voorwaarde kan nooit worden voldaan. Het feit dat wij overigens dikwijls de economische norm overtreden, verandert niets aan het karakter van de norm.

Ik kan mij dus ook niet verenigen met de redenering dat doelmatigheid een tautologisch begrip is, zonder enige richtende inhoud. Volgens deze opvatting zou doelmatigheid niets anders kunnen betekenen dan dat de handelende mens, gegeven zijn capaciteiten en de omstandigheden op het ogenblik van het handelen, naar maximale behoeftenbevrediging streeft, en dit is met de feiten steeds in overeenstemming. Nu moet ik toegeven dat wanneer ik onder doelmatig streven versta een streven naar maximale bevrediging van gegeven behoeften bij gegeven middelen, met inbegrip van kennis, inzicht, techniek en organisatie, dit weinig verhelderend zou zijn. Wanneer wij echter onder doelmatig streven mede verstaan een streven naar uitbreiding van kennis en inzicht, verbetering van techniek en organisatie, verruiming van beskikkingsmacht, en verheffing van het niveau van het verlangen door een meer verantwoorde keuze van doeleinden en behoeften, dan verlaten wij de statische visie en naderen wij dichter het probleem van de geroepen mens in zijn situatie.

Ik zou dus onder de economische norm der doelmatigheid willen verstaan dat beginsel van menselijk handelen, volgens hetwelk de handelende mens zijn doeleinden op zodanige wijze kiest en verwerkelijkt, en zijn middelen op zodanige wijze kiest en aanwendt, dat de situatie waarin hij verkeert, voorzoveel het te verwachten effect van zijn handelen betreft, zoveel mogelijk en in toenemende mate gaat beantwoorden aan de maatstaven die hij aanlegt in overeenstemming met de roeping die hem als mens onderscheidt, en zoals hij die in eigen vrijheid en verantwoordelikheid verstaat.

Ik ben mij ervan bewust dat mijn amateuristisch filosoferen aan allerlei critiek en bedenking onderhevig is, ook afgezien van de noodzakelijke beknoptheid die ik moest betrachten. Misschien zal iemand zeggen dat het meer humanistisch dan christelijk is, of meer christelijk dan calvinistisch. Misschien zal er accommodatie met heidens gedachtengoed in worden gevonden, of zullen sporen van ketterijen worden gesignaleerd. 
Een ander zal dit filosoferen onwetenschappelijk, metafysisch, ideologisch of speculatief vinden. Belangrijker dan dit opplakken van etiketten vind ik de tegenwerping, dat het simultaan realiseren van de veelzijdige normativiteit in de concrete situatie een onmogelijke zaak is, en dat wij de handelende mens niet met dergelijke ingewik kelde schema's moeten lastig vallen: wij zouden hem daarmee in verwarring brengen of tot verstarring doen komen. Ik haast mij echter op te merken, dat ik alleen een poging tot theoretische analyse van het economische als zodanig heb willen ondernemen. Wanneer men om een praktische raadgeving voor een goede ontplooiing van het menselijk leven en samenleven vraagt, kan ik er alleen op wijzen dat die reeds beschikbaar is, want de vervulling der wet is niets anders dan liefde. Dat kennen voor liefhebben noodzakelijk is, en dat dienen erop volgt, is vanzelfsprekend. Dat het liefhebben van God en de naaste ook liefde in de relatie tot het zelf en tot de dingen medebrengt, leert enig nadenken.

Een andere belangrijke tegenwerping ligt in de vraag naar het nut van dit soort beschouwingen voor de praktijk van het economisch leven en voor de beoefening van de vakwetenschap der economie. Het is immers duidelijk dat wij ons bij ons zogenaamd filosoferen met onze gedachten wel op zeer grote afstand hebben bevonden van de dagelijkse praktijk in de economische kring en van de in hoofdzaak rechtstreeks daarop gerichte theoretische analyse, waar men criteria als efficiency, rendabiliteit, productiviteit, continuïteit, liquiditeit, solvabiliteit en dergelijke hanteert. Deze criteria zijn echter verschijningsvormen van de economische norm der doelmatigheid in een situatie waarin men gewend is de waardering van middelen en doeleinden te doen geschieden door herleiding van de waarden der dingen op geld. De gewichten van de tegen elkaar afgewogen waarden worden in geld uitgedrukt. In het maat schappelijk verkeer worden de geldelijke waarderingen met elkander geconfronteerd. Zo ontstaan geldswaarden van goederen en diensten, en zo kan het in geld uitdrukbaar nettoresultaat maatstaf bij bepaalde belangrijke economische beslissingen worden. De invoering van het geldgebruik in het ruilverkeer heeft tot een enorme vergemakkelijking van het economisch proces en daarmee tot een grote toeneming van de welvaart in vele landen geleid.

Het gevaar is echter niet denkbeeldig, dat deze stand van 
zaken tot een afdamming van de economische levensstroom in een eigen kanaal, d.w.z. tot een absolutering van het in geldswaarden gevangen economische, en tot een scheeftrekken van de situatie voert, hetgeen zich uiteindelijk op allerlei plaatsen en tijden onverwachts wreekt in bedreiging en aantasting van de menselijke waardigheid. De praktisch werkzame economen en de wetenschappelijk analyserende economisten zij derhalve een zekere filosofische bezinning toegewenst bij de critische beoordeling van situaties en bij het opwerpen van hypothesen, opdat de fundamentele waarden van het menselijk leven niet in het vergeetboek geraken.

Vrije Universiteit, Amsterdam,

T. P. van der Kooy. Nederland. 